\title{
The rhetorics of feminism: readings in contemporary cultural theory and the popular press
}

Lynne Pearce; Routledge, London and New York, 2004, 256p, ISBN 0-4152-

8183-0 £24.00 (Pbk); ISBN 0-4152-8182-2 £80.00 (Hbk)

This book is about writing and thought and the relationship between them. Through the analysis of the rhetoric of 20 odd years of feminist discourse, Pearce aims at 'rooting out the relationship between how thought is made and how it is expressed' (p. 147). This is a complex book, offering a piercing dissection of the innovations in feminist writing from the 1970s to the 1990s, through detailed analysis of academic and popular feminist texts. It also refers to popular journalism, film and television documentary. These are suggestive reflections on the rhetorical innovations of feminism including: its complex and evolving deployment of pronouns; the growth of 'metaphorical thought' (particularly the productivities of the 'body metaphor'); and an identification of what she terms a 'recourse to narrativization and renarrativization' (p. 212). The book ends with a discussion of the 'temporal standpoints' that Pearce reads as positioning subjects in increasingly complex temporalities (she cites the events in the US of September 2001 as an indicative moment here). Never less than thought provoking and frequently also generous and revelatory, these readings demonstrate how texts work, how they persuade and how crucial, politically, this rhetorical 'work' is.

Pearce organizes the book into two parts, pronouns and arguments. In part one, 'pronouns', she examines the deployments of 'I's and 'We's' in popular and academic feminist texts, showing why some texts are more rhetorically persuasive than others. Exploring the 'use and development of strategies of first person enunciation' (e.g. Benjaminesque and 'strategic'), explored through detailed textual analysis of Annette Kuhn, Natasha Walters, Espeth Probyn and bell hooks, among others, Pearce also notes how feminist thought and writing has been misrepresented and misremembered and which rhetorical strategies have enabled such misrememberings. For instance, Pearce explains why the polemic of Greer and Millet in the 1970s (a form of rhetoric which she argues has recently been largely abandoned by academic feminism) is remembered as dominated by the first person despite its (actual) sparing use of that pronoun.

But the deployment of these 'I's and 'we's' is not left here; rather, Pearce argues that, despite the development of innovative and complex pronoun use, these highly sophisticated elaborations are consumed in a context wherein the enunciation of the first person 'may be seen as symptomatic' of 'the privatization of culture'. These considerations with reading and context are central to the book's concerns; the persuasiveness and sophistication of feminist discourse is dissected to demonstrate the ways texts have been read, or misread. For example, Pearce revisits the so-called 'culture wars' centring on Martha 
Nussbaum's attack on Judith Butler in 1999 (Chapter 5) and explores how Butler's 'mode of hypothesizing' (p. 162) might be seen as vulnerable to reductive (though she doesn't use the term) readings such as those of Nussbaum (and, Pearce implies elsewhere, too, not least in teaching contexts). For Pearce this is evidence for the need to be alert to the 'rhetorical politics of contemporary thought'. She concludes that the example demonstrates 'the enduring power of, and need for, that "single declarative sentence" of classical rhetoric: even those texts which despise and eschew it in and of themselves cannot escape the readers construction of the same' (p. 165, original italics). The book then serves to illustrate the ways in which texts work, their 'nuts and bolts' but also stresses, in keeping with poststructuralists insights, the fragility of the process, the risks posed by the contexts of reading, as well as the rhetorical successes.

The book offers a valuable reminder to some, and introduction to others, of the concepts of classical rhetoric and their contemporary inflections; my use of an 'example' in the above paragraph, for instance, is a deployment of what Pearce argues is a form of argumentation which is so commonplace as to have become 'a ... rhetorical tool in its own right'. The book is dedicated to students writing theses and indeed it makes an important study for anyone embarking on a thesis in the humanities or social sciences but equally, I would suggest, for anyone interested in questions of the relationship between writing, thinking and reading. However, the real achievement of this book is, for me, be the reminder that all writing employs rhetorical strategies and that the critical pleasures of exploring these enable a reading experience of the most active - in the political as well as in the sense of 'alert' - kind. Pearce both offers here readings of academic and popular feminist texts and provides a mapping of the rhetorical terrain of 20 years of feminist writing but, crucially, the book also demonstrates what it purports to be describing, subtly alerting the reader to the means by which the book as well as the texts described, persuades. Reading the book is therefore to participate in its project; the reader can hardly help but perform the analytical moves that Pearce makes, highly persuasive at the same time as instructing the reader in how it persuades.

doi: 10.1057 /palgrave.fr. 9400344

Sadie Wearing

\section{Alice Guy Blaché: lost visionary of the cinema}

Alison McMahan; Continuum, New York and London, 2002, 384p, ISBN 0-8264-5158$6 £ 45.00$ ( $\mathrm{Hbk})$

One of the tasks film feminism set itself at its outset was to reclaim its lost histories. Organizing a spate of film festivals in the early 1970s, which showcased 